\title{
Peripherally-Acting Opioids
}

\author{
Howard S. Smith, MD
}

From: Albany Medical College, Albany, NY.

Dr. Smith is Associate Professor and Academic Director of

Pain Management for Albany Medical College Department of Anesthesiology, Albany, NY.

Address correspondence: Howard S. Smith, MD

Associate Professor \& Academic Director of Pain Management Albany Medical College

Department of Anesthesiology 47 New Scotland Avenue; MC-131

Albany, New York 12208

E-mail: smithh@mail.amc.edu

Disclaimer: There was no external funding in the preparation of this manuscript.

Conflict of interest: None.

Free full manuscript: www.painphysicianjournal.com
Opioids are broad-spectrum analgesics with potent pain-relieving qualities but also with potential adverse effects related to both short-term and long-term therapy. Researchers have attempted to alter existing opioid analgesics, utilize different routes/ formulations, or combine opioid analgesics with other compounds in efforts to improve analgesia while minimizing adverse effects. Exogenous opioids, administered in efforts to achieve analgesia, work by mimicking the actions of endogenous opioids. Endogenous opioids and their receptors are located in the brain (supraspinal areas), spinal cord, and periphery. Although opioids and opioid receptors in the brain and spinal cord have received much attention over many years, peripheral endogenous opioid analgesic systems have only been extensively studied during the past decade. It has been known since 1990 that following injection into the rodent hindpaw, D-Ala², N-Me-Phe 4 , Gly ${ }^{5}$-ol-enkephalin (DAMGO) [a muopioid receptor agonist] probably exerts its antinociceptive effects locally, since the doses administered are too low to have an effect in the central nervous system (CNS). This notion has been supported by the observation that the quaternary compound morphine methyliodide, which does not as readily cross the bloodbrain barrier and enter the CNS, produced antinociception following intradermal administration into the hindpaw, but not when the same dose was administered systemically (subcutaneously at a distant site). With a growing appreciation of peripheral endogenous opioids, peripheral endogenous opioid receptors, and peripheral endogenous opioid analgesic systems, investigators began growing hopeful that it may be possible to achieve adequate analgesics while avoiding unwanted central untoward adverse effects (e.g. respiratory depression, somnolence, addiction). Peripherally-acting opioids, which capitalize on peripheral endogenous opioid analgesic systems, may be one potential future strategy which may be utilized in efforts to achieve potent analgesia with minimal side effects.

Key words: Pain, opioids, immune cells, peripherally-acting opioids (PAO), leukocytes, inflammatory pain, peripheral analgesia

Pain Physician 2008; 11:S121-S132 t has been well appreciated for many decades that inflammatory mediators from inflammation of peripheral tissues can lead to/promote pain, however, it has only been in the past decade that a gradual appreciation of the body's peripheral endogenous opioid analgesic system (PEOAS) has begun. The crucial elements of this system are leukocytederived opioids which are secreted from leukocytes accumulating at sites of peripheral inflammation. Inflammation increases peripheral leukocyte-derived opioids as well as peripheral opioid receptors. Inflammation in the periphery leads to an increase in the number/efficiency of opioid receptors on primary afferent neurons. Attempts to mimic or augment this peripheral analgesic system may potentially yield analgesia without central untoward adverse effects 
(e.g. respiratory depression, somnolence, addiction). The concept of peripheral opioid analgesia became more accepted when in 1990 following injection

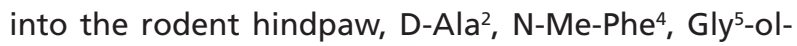
enkephalin (DAMGO) (a muopioid receptor agonist) was believed to exert its antinociceptive effects locally, since the doses administered are too low to have an effect in the central nervous system (CNS). This notion has been supported by the observation that the quaternary compound morphine methyliodide which does not as readily cross the bloodbrain barrier and enter the CNS, produced antinociception following intradermal administration into the hindpaw, but not when the same dose was administered systemically (subcutaneously at a distant site).

Although peripheral opioid receptors are largely expressed by primary sensory neurons (1), they are functionally inactive under most basal conditions. However, with tissue injury/inflammation, the action of bradykinin on the B2 receptor improves efficiency of muopioid receptor (MOR) coupling to $\mathrm{G} \alpha$ and promotes MOR signaling (2).

There are multiple ways by which endogenous opioids can gain access to peripheral sites of tissue insult to activate peripheral MORs. Cannabinoid (CB) agonists binding to peripheral $\mathrm{CB}(2)$ receptors results in $\mathrm{CB}(2)$ activation, with subsequent stimulated release of $\beta$ endorphin from keratinocytes in the skin (3).

In addition to the beta-endorphin/mu-opioid receptor (system which has been identified in human epidermis), Tominaga and colleagues (4) performed reverse transcription-PCR and immunohistochemical analyses on cultured ketatinocytes and normal skin from humans. The analyses revealed that epidermal kertinocytes express kappa-opioid receptor and its ligands, DynA (1-17) and DynA (1-8).

Moreover, another potential mechanism in which peripherally-acting opioids (PAOs) may affect nociception is via effects on $\alpha_{2}$-adrenergic receptormediated- and/or $\mathrm{A}_{1}$-Adenosine receptor-mediated antinociception.

\section{Peripheral Opioid Receptors and InfLAMMATION}

Peripheral opioid receptors are synthesized in the dorsal root ganglion (DRG) and intraaxonally transported (as well as in some cases along with their mRNA) to peripheral sensory nerve endings $(5,6)$. Opioid receptors belong to the family of 7 transmembrane domain G-protein coupled receptors and may be involved in multiple processes as well as being involved in regulatory processes (7). The binding of opioid peptides (OPs) to opioid receptors (ORs) will cause OR activation and coupling to inhibitory G-proteins $\left(G_{i / 0}\right)$ resulting in inhibition of high-voltage activated calcium channels, tetrodotoxin-resistant sodium channels, and decreased levels of neuronal cyclic adenosine monophosphate (8).

All the 3 opioid receptor subtypes $(\mu, \delta$, and $\kappa$ ) belong to the superfamily of G-protein-coupled receptors (GPCR) that mediate the actions of endogenously produced opioid neuropeptides and exogenously administrated opiate drugs (9).

The G-proteins exist as heterotrimers derived from 3 different primary classes of subunits: $\mathrm{G}_{\alpha^{\prime}} \mathrm{G}_{\beta^{\prime}}$ and $\mathrm{G}_{\gamma}$ (10). An opioid receptor is activated by agonist forcing the GDP bound to be replaced to the $\alpha$-subunit by GTP, which then forces the dissociation of $G_{\alpha}$ and $\mathrm{G}_{\beta \gamma}$ subunits. The activated $\alpha$ - and $\beta \gamma$-subunits can each mediate downstream effects providing a locus for the 2 entities to couple to multiple cellular effectors like enzymes and ion channels (11).

Askari et al (12) showed that the carrageenan administration increased G-protein subunits. A single injection of morphine alone and in the presence of inflammation produced the same upregulation of $G_{\text {ailo }}$ mRNA. Thus, inflammation in the periphery did not influence the increase in the $G_{\text {ailo }}$ mRNA levels following the administration of analgesic dose of morphine (12). Acute treatments with the analgesic dose of morphine alone were not able to change the expression levels of $G_{\beta}$ (13). While administration of analgesic doses of morphine $30 \mathrm{~min}$ before a carrageenan injection markedly increased the $G_{\beta}$ mRNA levels (12). Voltagedependent calcium channels appear to be selectively regulated by $\mathrm{G}_{\beta \gamma}$ complexes to produce analgesia (14). The GIRK channels have been the first effectors shown to be regulated by $\mathrm{G}_{\beta \gamma}$ subunits (15). Askari et al (12) have provided evidence for the involvement of the $G_{\beta}$ subunit in the morphine analgesia. The $G_{\beta}$ mRNA levels are upregulated in spinal cord when nociception is fully established (12).

Askari and colleagues (12) suggested that the expression level of G-protein $\left(G_{\beta}\right)$ genes following the acute administration of morphine between animals with and without inflammation may influence, at least in part, some of the difference in the analgesic responsiveness of these 2 groups (12).

Additionally, MOR agonists may inhibit transient receptor potential vanilloid-1 (TRPV1)-mediated in- 
creases in intracellular calcium in a kidney cell line (16) and may decrease capsaicin-induced TRPV1 currents via $\mathrm{G}_{\mathrm{i} / \mathrm{o}}$ and the cyclic adenosine monophosphate pathway in DRG cells from animal models of peripheral inflammation (17).

Opioid peptides binding to their receptors may lead to attenuation of the excitability of nociceptors, impaired propagation of action potentials, and inhibition of the release of excitatory neurotransmitters and proinflammatory neuropeptides (e.g. substance $P$, calcitonin gene-related peptide) from nociceptor endings which produce analgesia (8).

Inflammation in the periphery gives rise to increased synthesis and axonal transport of opioid receptors in DRG neurons with resultant MOR, upregulation (with increases in MOR binding and immunoreactivity) and enhanced MOR G-protein coupling (with increased MOR agonist efficacy) at peripheral nerve terminals (18-22). These effects may be related to neuronal electrical activity, production of proinflammatory cytokines (e.g. IL-1 $\beta$, IL-6, TNF $\alpha$ ), and nerve growth factor (NGF) $(21,23-25)$. Perhaps the major contributor to up-regulation in the number and efficacy of sensory neuron MORs is nerve growth factor (25). NGF is increased in peripheral inflammation and acts on nociceptive neurons via interaction with the tyrosine kinase receptors TrkA and p75 NTR (26). NGF is known to increase enkephalin-binding sites in cell culture (27) and raise diprenorphine binding sites in isolated DRG (1).

Mousa et al (25) found that during localized inflammatory pain endogenous NGF enhances the susceptibility to locally applied opioids by an up-regulation in the number and efficacy of MORs in primary afferent neurons. This is established in several ways: 1) co-localization of muopioid receptor-immunoreactivity (MOR-ir) neurons in DRG with the sensory neuron marker calcitonin gene-related peptide (CGRP) and the majority of these co-expressing the NGF receptors TrkA and $\mathrm{p} 75^{\mathrm{NTR}} ; 2$ ) increased NGF concentrations retrogradely transported within the sciatic nerve innervating Complete Freund's Adjuvant (CFA) or NGF-treated tissue; 3) up-regulation of MOR predominantly in TrkA positive DRG ipsi, but not contralateral to intraplantar (i.pl.) CFA or NGF and its prevention by disruption of the retrograde axonal transport; 4) enhanced peripheral transport of MOR along the sciatic nerve following CFA or NGF; 5) increased number of MOR-ir sensory nerve endings within CFA or NGF-treated skin; and 6) potentiation of dose-dependent antinocicep- tive effects of i.pl. fentanyl following local CFA or NGF, which are naloxone reversible (25). All these changes are prevented by neutralization of local NGF with an i.pl. NGF-specific antiserum (25).

Chen and colleagues found (28) that the constitutively activated TrkA/phosphatidylinositol 3-kinase/ Akt (protein kinase B)/NF-KB survival cascade mediates dor expression during nerve growth factor (NGF)-induced differentiation of PC12h cells. Biochemical experiments showed that constitutive phosphorylation of Akt and IKB $\alpha$ correlates with NGF-induced dor expression. Overexpression of the transcriptional activator NF-kB/p65 increased dor promoter activity (28). Overexpression of the NF-KB signaling super inhibitor mutant IKB $\alpha$ (S32A/S36A) abolished the effect of p65 and blocked NGF-induced activation of NF-KB signaling, resulting in a significant reduction in dor promoter activity (28). Treatment with SN50, an NF-KB-specific nuclear translocation peptide inhibitor, inhibited the translocation of NF- $\mathrm{KB}$, resulting in a reduction of dor mRNA (28). The gel shift assay supported the fact that there exists an NF-KB-binding site on the dor promoter. RNA interference experiments using NF- $\mathrm{KB} / \mathrm{p} 65$ small interfering RNA confirmed that NF-KB signaling is required for dor expression (28). Furthermore, Chen et al (29) have shown that direct association of p65 with the promoter is important in NGF-induced dor promoter activity. In addition, tumor necrosis factor (TNF) treatment activates MEKK3, which may activate NF-kB (30), and conceivably may affect opioid receptors.

Additional effects from which may enhance opioid efficacy in the periphery include an increase in the number of nociceptor endings and disruption of the perineural barrier which may facilitate access of opioid peptides to their receptors $(8,25,31)$.

Clark et al (32) concluded that acute morphine administration of doses as low as $0.1 \mathrm{mg} / \mathrm{kg}$ reduces peri-incisional cytokine expression. A reduction in neutrophil infiltration does not fully explain this effect, and keratinocytes may be responsible for some peri-incisional cytokine production (32).

In order to achieve effective peripheral endogenous opioid analgesia, the body not only needs to have adequate numbers of functional opioid receptors on primary afferent neurons, but particularly important is that opioid-containing leukocytes need to get out of the circulating blood to the inflamed site, as well as secrete adequate amounts of opioid peptides. Brack et al (33) concluded that early inflammation is appar- 
ently not limited by the number of opioid-containing leukocytes but by OR availability.

\section{Opioids Peptides and Inflammation}

\section{Leukocyte Accumulation at the Site of Periph- eral Inflammation}

The process of leukocytes traveling to the inflamed site involves a well-coordinated series of events. Initially, leukocytes traveling slower and closer to the blood vessel wall begin a process known as "rolling," along the endothelial cell wall mediated largely via L-, $\mathrm{P}-$, and E-selectins.

Leukocytes are then attracted to the portion of the blood vessel wall by the inflammatory sites activated by chemokines (which are released from endothelial and inflammatory cells) and presented on the endothelium. This leads to up-regulation and increased avidity of integrins which mediate the next step of adhesion, the firm adhesion of leukocytes to endothelial cells via intercellular adhesion molecule-1 (ICAM-1). ICAM1 expressed on vascular endothelium is up-regulated with inflammation and also recruits immunocytes containing opioids to promote local control of inflammatory pain (34). Leukocytes then transmigrate through the endothelium via diapedesis which is mediated predominatly by the platelet-endothelial cell adhesion molecule-1 (PECAM-1) (35). However, Machelska et al (36) showed that swim stress produced potent opioidmediated antinociception in inflamed tissue, unaffected by bkockade of PECAM-1. Blockade of L- and P-selectins by fucoidin, or of alpha(4) and beta(2) by monoclonal antibodies, completely abolished peripheral stress-induced antinociception (36). This coincided with a $40 \%$ decrease in the migration of opioid-containing leukocytes to inflamed tissue. Machelska and colleagues (36) suggested that selectins and integrins alpha(4) and beta(2), but not PECAM-1, are important molecules involved in stress-induced opioid-mediated antinociception in inflammation and they cautioned the use of anti-inflammatory treatments applying antiselectin, anti-alpha(4) and anti-beta(2) strategies, because they may impair intrinsic pain inhibition; although strategies which may boost the functions of selectins and inegrin alpha(4) and beta(2) may augment analgesia. L-selectin, integrins $\beta 2$, and CXCR2 are co-expressed by opioid-containing leukocytes (36-38) and adhesion molecules (e.g. P- and E-selectins, ICAM1, PECAM-1) are up-regulated on endothelium in in- flamed paw tissue (34,36-39). Expression of CXC1 and CXCL 2/3 mRNAs and proteins significantly increase during inflammation $(38,40)$.

Pretreatment of rats with a selectin blocker (fucoidin), selective antibodies against ICAM-1, integrins $\alpha 4$ and $\beta 2$, or against chemokines CXCL1 and CXCL2/3 significantly diminishes the number of opioid-containing immune cells which accumulate in inflamed tissue $(34,36,38,39)$, and thus, results in inhibition of endogenous peripheral opioid analgesia (41).

Neurokinins (e.g., substance P) also contribute to peripheral leukocyte recruitment in inflammation. Leukocyte recruitment appears to involve chemotaxis through $\mathrm{NK}_{1}$ receptors on leukocytes (42). Rittner et al (42) treated rats intraperitoneally and intrathecally with peripherally restricted (SR140333) or bloodbrain barrier-penetrating $(\mathrm{L}-733,060) \mathrm{NK}_{1}$ receptor antagonists and were evaluated for paw pressure thresholds, numbers of infiltrating opioid-containing leukocytes and leukocyte subpopulations, expression of adhesion molecules, $\mathrm{NK}_{1}$ receptors, and chemokines 24 - 48 hours after complete Freund adjuvant-induced hind paw inflammation (42). Systemic and peripherally selective, but not intrathecal, $\mathrm{NK}_{1}$ receptor blockade reduced stress-induced antinociception (control: $177 \pm 9 \mathrm{~g}, \mathrm{~L}-733,060: 117 \pm 8 \mathrm{~g}$, and control: $166 \pm 30$ g, SR140333: $89 \pm 3$ g; both $p<0.05, t$ test) without affecting baseline hyperalgesia (42). In parallel, local recruitment of opioid-containing leukocytes was decreased (L-733,060 and SR140333: $56.0 \pm 4.3$ and 59.1 $\pm 7.9 \%$ of control; both $p<0.05$, $t$ test) (42). NK ${ }_{1}$ receptors were expressed on peripheral neurons, infiltrating leukocytes and endothelial cells. Peripheral $\mathrm{NK}_{1}$ receptor blockade did not alter endothelial expression of intercellular adhesion molecule-1 or local chemokine and cytokine production, but decreased polymorphonuclear cell and macrophage recruitment (42). Rittner and colleagues (42) concluded that endogenous inhibition of inflammatory pain is dependent on $\mathrm{NK}_{1}$ receptor-mediated recruitment of opioid-containing leukocytes (Fig. 1).

\section{Leukocyte Secretion of Opioid Peptides}

Immune cells possess everything needed to produce opioid peptides (e.g. proopiomelanocortin [POMC] processing into functional $\beta$-endorphin) (43). Multiple mediators which are enhanced with inflammation may facilitate OP release from leukocytes in a receptor selective and calcium-dependent fashion in- 


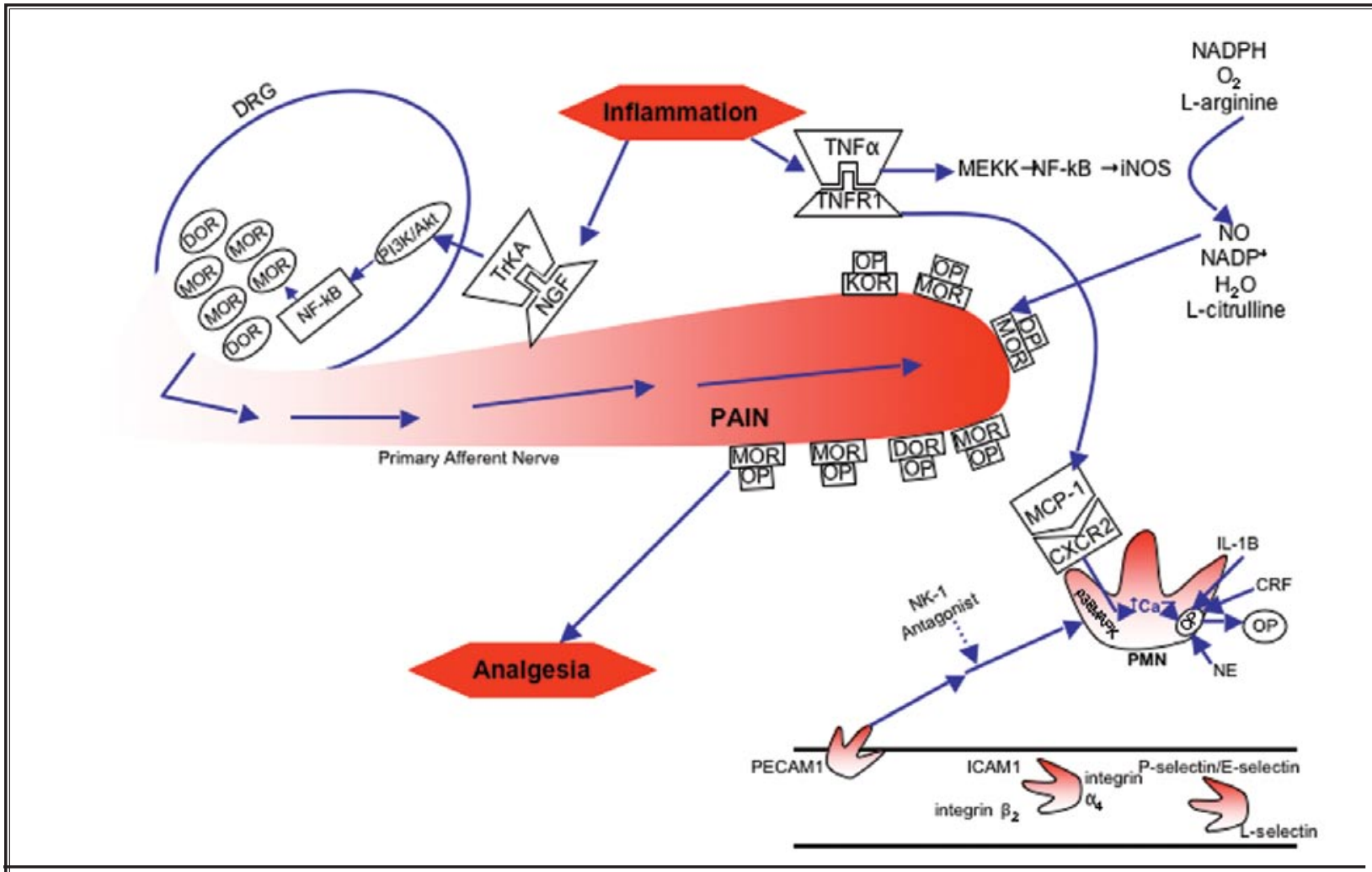

Fig. 1. Peripheral endogenous opioid analgesia system.

cluding corticotrophin-releasing factor (CRF), interleukin-1 $\beta$ (IL-1 $\beta$ ) (44-47), and chemokines (e.g. CXCL2/3) (48).

Injections of CRF and IL-1 $\beta$ into inflamed rodent paws yield analgesia which is reversible by CRF, IL- $1 \beta$, and opioid receptor antagonists $(38,44,49,50)$. In an animal model of tonic pain, that is, Complete Freuds Adjuvant (CFA) hindpaw inflammation, Mousa et al (51) systematically investigated CRF's ability to modulate inflammatory pain at 3 levels of pain transmission (brain, spinal cord, and periphery) by algesiometry following the intracerebroventricular, intrathecal, and intraplantar application of low, systemically inactive doses of CRF. At each level, CRF elicits potent antinociceptive effects, which are dose dependent and antagonized by local, but not systemic CRF receptor antagonist alpha-helical CRF indicating CRF receptor specificity (51). Local administration of CRF together with the opioid receptor antagonist naloxone dose- dependently reversed CRF's antinociceptive effects at each of these three levels of pain transmission (51). Injections of norepinephrine into inflamed tissue also yields analgesia which is reversible by $\alpha 1-, \alpha 2-$, and $\beta 2-$ adrenergic receptor antagonists as well as MOR and DOR-antagonists and antibody directed against $\beta$-endorphin (47). However, perhaps the most predominant contributor promoting leukocytes, not only to accumulate but also to secrete opioid peptides, may be chemokines.

Rittner et al showed (52) that $\beta$-endorphin (END) and Met-enkephalin (ENK) were colocalized with the primary (azurophil) granule markers CD63 and myeloperoxidase (MPO) within PMN. END and ENK release triggered by a CXCR $1 / 2$ ligand in vitro was dependent on the presence of cytochalasin B (CyB) and on p38 MAPK, but not on p42/44 MAPK. In addition, translocation of END and ENK containing primary granules to submembranous regions of the cell was abolished by 
the p38 MAPK inhibitor SB203580 (52). In vivo CXCL2/3 reduced pain in rats with CFA-induced hindpaw inflammation. This effect was attenuated by intraplan$\operatorname{tar}$ (i.pl.) antibodies against END and ENK and by i.pl. p38 MAPK inhibitor treatment. Rittner and colleagues (52) concluded that their findings indicate that END and ENK are contained in primary granules of PMN, and that CXCR1/2 ligands induce p38-dependent translocation and release of these opioid peptides to inhibit inflammatory pain.

\section{Chemokines}

Chemokines (chemotaxic cytokines) are a family of small proteins which play a prominent role in the trafficking of immune cells and in the orchestration of inflammatory responses (53). It has been suggested that the chemokine monocyte chemoattractant protein-1(MCP-1/CCL2) and its receptor (CCR2) may play an important role in the genesis of neuropathic pain as MCP-1 and CCR2 are not normally expressed in the DRG (54). However, the expression of both of these molecules increases in DRG neurons in association with nerve injury, and application of MCP-1 to CCR2 expressing neurons strongly depolarizes them $(54,55)$. Furthermore, CCR2 knockout mice show impaired development and maintenance of neuropathic pain (56). The results of Jung et al (53) suggest that MCP-1 and CCR2 are up-regulated by sensory neurons following peripheral nerve injury, and might participate in neural signal processing which contributes to sustained excitability of primary afferent neurons.

Garcia-Ramallo et al (57) suggested chemokines synthesized by resident immune cells serve as a major mechanism for leukocyte recruitment during local inflammation.

In the early phase of inflammation, polymorphonuclear cells (PMNs) are the major source of opioids. Their recruitment is governed by ligands at the chemokine receptor CXCR2. Rittner et al (48) examined whether chemokines can also induce opioid peptide secretion from PMN and thus inhibit inflammatory pain. In rats with hindpaw inflammation, intraplantar injection of CXCL2/3, but not of the CXCR4 ligand CXCL12, elicited naloxone-reversible (i.e., opioid receptor mediated) mechanical and thermal analgesia, which was abolished by systemic PMN depletion (48). Both CXCR1/2 and CXCR4 ligands induced PMN chemotaxis, but only CXCR1/2 ligands triggered opioid release from human and rat PMN in vitro (48). This release was unaltered by extracellular $\mathrm{Ca}^{2+}$ chelation, was mimicked by thapsigargin, and was blocked by inhibitors of the inositol 1,4,5-triphosphate receptor $\left(\mathrm{IP}_{3}\right)$ and by intracellular $\mathrm{Ca}^{2+}$ chelation, indicating that it required $\mathrm{Ca}^{2+}$ from intracellular but not extracellular sources (48). Furthermore, release was partially reduced by phosphoinositol-3-kinase (PI3K) inhibitors. Adoptive transfer of allogenic PMN into PMN-depleted rats reconstituted CXCL2/3-induced analgesia, which was inhibited by prior ex vivo chelation of intracellular $\mathrm{Ca}^{2+}$. These findings demonstrate that, beyond cell recruitment, CXCR2 ligands induce $\mathrm{Ca}^{2+}$-regulated opioid release from PMN and thereby inhibit inflammatory pain in vivo (48).

Although the analgesic effect of a single dose of exogenous $\mathrm{CXCL} 2 / 3$ only lasts $10 \mathrm{~min}$, endogenous CXCR $1 / 2$ ligands are continuously produced during inflammation (48). Therefore, it is conceivable that endogenous CXCR1/2 ligands might constantly stimulate infiltrating PMN to release opioid peptides. Data obtained in postoperative patients that have shown a role of immune cell-derived endogenous opioid peptides in pain control. It has previously shown that coinjection of CFA and CXCL2/3 does not enhance hyperalgesia and that local CXCL2/3 injection into noninflamed tissue elicits PMN recruitment without hyperalgesia. Thus, additional chemokine application should not worsen pain and $\mathrm{PMN}$-specific chemokines might be useful for treatment of pain states when PMN are predominant (e.g., in acute inflammation or postoperatively) (48).

\section{Other Leukocytes Secreted Opioid Peptides}

Opioid Peptides Other than Endorphins, Enkephalins and Dynorphins May Be Involved in the PEOAS

Endomorphins

Endomorphin (EM-1 and EM-2) are tetrapeptides located within the mammalian central nervous system and immune tissues, with high affinity and specificity for muopioid receptors (58). Most of the literature has focused on the analgesic properties of EM-1 and EM-2 in animal models of neuropathic or neurogenic pain, but there is persuasive evidence emerging that EMs can also exert potent anti-inflammatory effects in both acute and chronic peripheral inflammation (58).

Endomorphin-1 (EM-1) (Tyr-Pro-Trp-Phe- $\mathrm{NH}_{2}$ ) and endomorphin-2 (EM-2) (Tyr-Pro-Trp-Phe- $\mathrm{NH}_{2}$ ) are 2 endogenous opioid peptides, initially characterized by Zadina et al (59), with high affinity and selectivity 
for the muopioid receptor. EM-1 exhibits selectivity of 4,000- and 15,000-fold for the muopioid receptor over the $\delta$ - and $\mathrm{k}$-opioid receptors respectively (59). Endormorphin-1 is widely and densely distributed throughout the brain and upper brainstem and endomorphin-2 is more prevalent in the spinal cord and lower brainstem. Endomorphins have also been detected in significant levels in immune cells of inflamed subcutaneous tissue (60).

The upregulation of MOR and of its endogenous ligands endomorphin-1 and endomorphin-2 in immunocytes suggests a potential involvement of these opioid peptides in the peripheral regulation of inflammatory pain (60). Labuz et al (61) examined peripheral antinociception elicited by exogenously applied EM-1 containing leukocytes to stress- and corticotrophinreleasing factor (CRF)-induced antinociception by applying behavioral (paw pressure) testing, radioligand binding, immunohistochemistry, and flow cytometry in rats with unilateral hindpaw inflammation induced with Freund's Adjuvant. EMs injected directly into both hindpaws produced antinociception exclusively in inflamed paws (61). Leukocyte-depleting serum decreased the number of immigrating opioid-containing immune cells and attenuated swim stress- and CRF-induced antinociception in inflamed paws. Both forms of antinociception were strongly attenuated by antibeta-endorphin and to a lesser degree by anti-EM-1 and anti-EM-2 antibodies injected into inflamed paws. Labuz and colleagues (61) concluded that exogenously applied and immune cell-derived EMs alleviate prolonged inflammatory pain through selective activation of peripheral opioid receptors. Exogenous EM-2 in addition to mureceptors also activated peripheral delta-receptors, which does not involve actions via other opioid peptides (61).

Li et al (62) used various nociceptive tests to show that EM-1 produced dose-dependent, naloxone-reversible analgesia after intraperitoneal administration in rats. Peripherally administered endomorphins are generally regarded as acting peripherally because of their rapid enzymatic degradation and low permeation through the bloodbrain barrier, very little EM actually reaches the central nervous system. Furthermore, the peak analgesic effect appeared later in the time course and was less pronounced than analgesia induced by intracerebroventricular or intrathecal EM (62).

Cardillo et al (63) described a novel endomorphin1 analogue (Tyr- ${ }_{L}^{-\beta}-$ Pro-Trp-Phe- $\mathrm{NH}_{2}$; [Endo1- $\beta-$ Pro]) more resistant to enzymatic hydrolysis than endomorphin-1 that acts as a $\mu$ opioid receptor agonist. Spampinato et al (64) report that Endo1- $\beta$-Pro, s.c. injected in the mouse is an effective antinociceptive agent in the tail flick $\left(\mathrm{ED}_{50}=9.2 \mathrm{mg} / \mathrm{kg}\right)$ and acetic acid-induced abdominal constriction $\left(E_{50}=1.2 \mathrm{mg} / \mathrm{kg}\right.$ ) tests.

Endo1- $\beta$-Pro may act, preferentially, through central and peripheral $\mu_{2}$ opioid receptors to produce antinociception and to inhibit gastrointestinal transit. Endo1- $\beta$-Pro is among the first endomorphin-1 analogues showing antinociceptive activity after systemic administration.

\section{Opioids: Central versus Peripheral Analgesia}

Opioid effects are mediated by central and peripheral opioid receptors. Labuz and colleagues (65) examined the relative contribution of each receptor population to antinociception elicited by systemically administered centrally penetrating opioids, and by loperamide (a peripherally restricted opioid). Nociception (abdominal writhes) was induced by intraperitoneally (i.p.) injected $0.6 \%$ acetic acid in mice (65). Labuz et al (65) analyzed opioid receptor expression in peritoneum by immunohistochemistry, antinociception after i.p. injected agonists at mu (morphine, loperamide)-, delta (SNC80)- and kappa (U50488)-receptors, and its reversibility by subcutaneously (s.c.) administered centrally penetrating antagonists $\beta$-funaltrexamine $(\mathrm{mu})$, naltrindole (delta), and nor-binaltorphimine (kappa), and by the peripherally restricted antagonist naloxone methiodide (NLXM). NLXM was also injected intracerebroventricularly (i.c.v.) before i.p. loperamide. $\mathrm{Mu}$, kappa, and, to a lesser degree, deltareceptors were expressed on peripheral nerve terminals in the peritoneum. The anatomical distribution of the opioid receptor staining was very similar to the staining for calcitonin gene-related peptide, a marker of sensory neurons. Morphine, U50488, and, to a lesser degree, SNC80, blocked acetic and acid induced writhes. These effects were reversed by $\beta$-funaltrexamine, nor-binaltorphimine, and naltrindole, respectively. NLXM (s.c.) reversed antinociceptive effects of morphine, SNC80, and $\mathrm{U} 50488$ by $57 \%, 80 \%$, and $47 \%$, respectively (65). Loperamide $(0.05 \mathrm{mg} / \mathrm{kg})$-induced antinociception was reversed by s.c. $\beta$-funaltrexamine and NLXM. Loperamide $(0.1 \mathrm{mg} / \mathrm{kg})$-induced antinociception was completely blocked by s.c. $\beta$-funaltrexamine but was only attenuated (by $50 \%$ ) by s.c. or i.c.v. NLXM (65). Labuz et al (65) concluded that systemically adminis- 
tered centrally penetrating mu, delta, and kappaagonists produced a substantial part of antinociception through peripheral opioid receptors. Higher dose loperamide-induced antinociception involved also central opioid receptors (65).

\section{Clinical Peripheral Opioid Analgesia}

Opioid receptors were detected, quantified, and characterized in homogenates from capsule/synovium and periosteum using radioligand binding assays (66). Receptor binding of the nonselective opioid [3H] naloxone to tissue homogenates was stereospecific and saturable, showing similar characteristics to that of brain tissue, although with lower binding capacities (66). The neuronal occurrence of 4 different enkephalins was demonstrated by immunohistochemistry in synovium, bone marrow, periosteum, and juxta-articular bone, whereas no neuronal dynorphin immunoreactivity was detected (66). Double-staining studies disclosed that enkephalins coexisted with substance $P$ in primary afferent fibers (66).

Mousa and colleagues (67) concluded that parallel to the severity of inflammation, $\beta$-endorphin and Met-enkephalin in immune cells and their opioid receptors (e.g. MORs, DORs) on intra-articular sensory nerve terminals are more abundant in patients with rheumatoid arthritis than in those with joint trauma and osteoarthrisits.

Forty separate randomized, controlled studies have examined the effects of intra-articular opioids on pain following knee surgery. Thirty-six of these studies were examined in detail by Kalso et al (68) as part of a systematic review (69). In general, a small amount of morphine administered into a sequestered site with a known local inflammatory process produces more analgesia (greater magnitude of pain relief or longer duration of pain relief) than a similar amount of morphine (or its equivalent) administered systemically (69). This is consistent with the observation that opioid receptors become expressed on peripheral afferent nerve terminals in the presence of inflammation (70) and the observation in multiple animal experiments and clinical studies that peripheral opioids are more effective in the presence of inflammation (71).

Likar et al (72) demonstrated analgesic efficacy of opioid injected into the knees of patients with osteoarthritis not undergoing surgery. Clinically, in the absence of inflammation or with injection into a site that does not limit systemic redistribution there appears to be little or no selective peripheral analgesic effects of opioids (69).

\section{Peripherally-acting Opioids}

Opioid analgesics with restricted access to the central nervous system peripherally-acting opioids (PAOs) may possess improved safety over opioids currently used in clinical practice (73).

Obara et al (74) demonstrated peripheral antinociception of $\mu$ opioid receptor agonists, morphine, DAMGO, endomorphin-1, and endomorphin-2 in neuropathic pain elicited by sciatic nerve ligation. All these agonists were more effective in alleviating allodynia after their i.pl., than after s.c. administration. Their antinociceptive effects appear to be mediated by local peripheral opioid receptors since the peripherally selective opioid receptor antagonist, naloxone methiodide, blocked the analgesia. Thus, this is in line with most of the studies reporting morphine effects after peripheral administration (75-77).

Recently, 6-amino acid-substituted derivatives of 14-O-methyloxymorphone were described as $\mu$ opioid receptor agonists with restricted penetration to the central nervous system $(78,79)$. Published pharmacological data from Furst et al (80) demonstrated that such derivatives produce long-lasting antinociception in acute inflammatory pain after subcutaneous (s.c.) administration, being more potent than morphine. It was also shown that morphine, a centrally acting $\mu$ opioid agonist, exerts its analgesic effects by both central and peripheral mechanisms, while the new opioids interact primarily with peripheral opioid receptors. Obara et al (73) assessed the antinociceptive effects of the 6-amino acid conjugates (glycine and phenylalanine), $\alpha$ - or $\beta$-orientated, 14-O-methyloxymorphone (Fig. 2) in rat models of inflammatory pain (induced by local intraplantar [i.pl.] formalin injection) and neuropathic pain (produced by ligation of the sciatic nerve) after local, i.pl. administration directly into the injured hindpaw and compared their antinociceptive effects to morphine.

Intraplantar administration of morphine and the 6-amino acid derivatives produced dose-dependent reduction of formalin-induced flinching of the inflamed paw, without significant effect on the paw edema (73). Local intraplantar (i.pl.) administration of the new derivatives in rats with neuropathic pain induced by sciatic nerve ligation produced antiallodynic and antihyperalgesic effects; however, the antinociceptive 


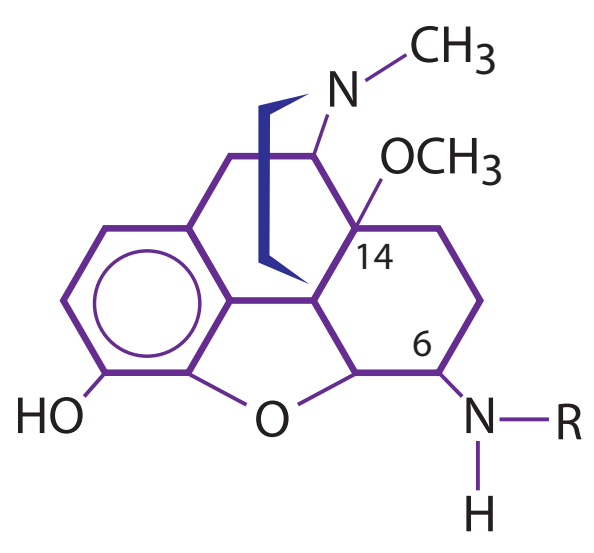

a-conjugates

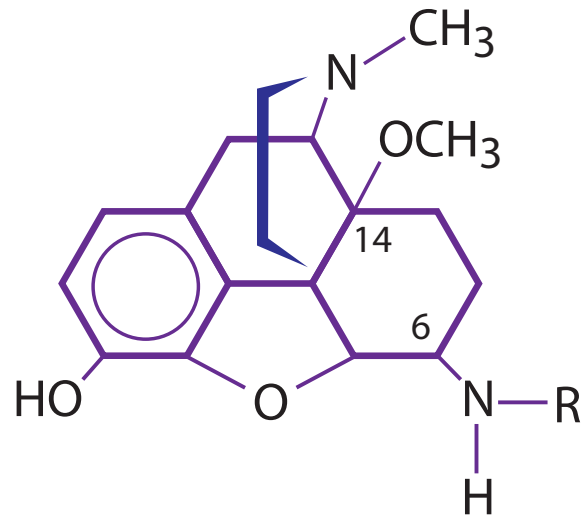

$\beta$-conjugates

Fig. 2. Peripheral-acting opioids. From Obara et al, 2007 (73).

activity was lower than that observed in inflammatory pain (73). In both models, the 6-amino acid derivatives and morphine at doses that produced analgesia after i.pl. administration were systemically (s.c.) much less active indicating that the antinociceptive action is due to a local effect (73). Moreover, the local opioid antinociceptive effects were significantly attenuated by naloxone methiodide, a peripherally acting opioid re- ceptor antagonist, demonstrating that the effect was mediated by peripheral opioid receptors (73). Obara et al (73) suggested their data indicate that the peripherally restricted 6-amino acid conjugates of $14-O$ methyloxymorphone elicit antinociception after local administration, being more potent in inflammatory than in neuropathic pain.

\section{References}

1. Chen JJ, Dymshitz J, Vasko MR. Regulation of opioid receptors in rat sensory neurons in culture. Mol Pharmacol 1997; 51:666-673.

2. Berg KA, Patwardhan AM, Sanchez TA, Silva YM, Hargreaves KM, Clarke WP. Rapid modulation of (micro)-opioid receptor signaling in primary sensory neurons. J Pharamcol Exp Ther 2007; 321:839-847.

3. Ibrahim MM, Porreca F, Lai J, Albrecht PJ, Rice FL, Khodorova A, Davar G, Makriyannis A, Vanderah TW, Mata HP, Malan PT, Jr. CB2 cannabinoid receptor activation produces antinociception by stimulating peripheral release of endogenous opioids. PNAS USA 2005; 102: 3093-3098.

4. Tominaga M, Ogawa H, Takamori K. Pos- sible roles of epidermal opioid systems in pruritus of atopic dermatitis. J Invest Dermatol 2007; 127:2228-2235.

5. Ninkovic M, Hunt SP, Gleave JR. Localization of opiate and histamine $\mathrm{H}_{1}$-receptors in the primate sensory ganglia and spinal cord. Brain Res 1982; 241: 197-206.

6. Bi J, Tsai N-P, Lin Y-P. Loh HH, Wei L-N. Axonal mRNA transport and localized translational regulation of k-opioid receptor in primary neurons of dorsal root ganglia. PNAS 2006; 103:19919-19924.

7. Smith HS. Mechanism and modulation of mu-opioid receptor agonist signaling. Journal of Cancer Pain and Symptom Palliation 2005; 1:3-13.

8. Stein C, Schäfer M, Machelska H. Attacking pain at its source: New per- spectives on opioids. Nat Med 2003; 9: 1003-1008.

9. Kieffer BL, Gaveriaux-Ruff C. Exploring the opioid system by gene knockout. Prog Neurobiol 2002; 66:285-306.

10. Hildebrandt JD. Role of subunit diversity in signaling by heterotrimeric G proteins. Biochem Pharmacol 1997; 54:325-339.

11. Tailor DA, Fleming WW. Unifying perspectives of the mechanisms underlying the development of tolerance and physical dependence to opioids. J Pharmacol Exp Ther 2001; 297:11-18.

12. Askari N, Mahboudi F, Haeri-Rohani A, Kazemi B, Sarrami R, Edalat R, Ahmadiani A. Effects of single administration of morphine on G-protein mRNA level in the presence and absence of inflamma- 
tion in the rat spinal cord. Scand $\mathrm{J} / \mathrm{m}$ munol 2007; 67:47-52.

13. Kaewsuk S, Hutamekalin P, Ketterman AJ, Khotchabhakdi N, Govitrapong P, Casalotti SO. Morphine induces shortlived changes in G-protein gene expression in rat prefrontal cortex. Eur J Pharmacol 2001; 411:11-16.

14. Herlitze S, Hockerman GH, Scheuer T, Catterall WA. Molecular determinants of inactivation and $\mathrm{G}$ protein modulation in the intracellular loop connecting domains I and II of the calcium channel alpha1A subunit. Proc Natl Acad Sci U S A 1997; 94:1512-1516.

15. Reuveny E, Slesinger PA. Activation of the cloned muscarinic potassium channel by $\mathrm{G}$ protein beta gamma subunits. Nature 1994; 370:143-146.

16. Vetter I, Wyse BD, Monteith GR, Roberts-Thomson SJ, Cabot PJ. The mu-opioid agonist morphine modulates potentiation of capsaicin-evoked TRPV 1 responses through a cyclic AMP-dependent protein kinase A pathway. $\mathrm{Mol}$ Pain 2006; 2:1-16.

17. Endres-Becker J, Heppenstall PA, Mousa SA, Labuz D, Oksche A, Schäfer M, Stein C, Zöllner C. Mu-opioid receptor activation modulates transient receptor potential vanilloid 1 (TRPV 1 ) currents in sensory neurons in a model in inflammatory pain. Mol Pharmacol 2007; 71:12-18.

18. Mousa SA, Zhang Q, Sitte N, Ji R, Stein $C$. Beta-endorphin-containing memorycells and mu-opioids receptors undergo transport to peripheral inflamed tissue. J Neuroimmunol 2001; 115:71-78.

19. Zöllner C, Shaqura MA, Bopaiah CP, Mousa SA, Stein C, Schäfer M. Painful inflammation-induced increase in $\mathrm{mu}$ opioid receptor binding and G-protein coupling in primary afferent neurons. Mol Pharmacol 2003; 64:202-210.

20. Shaqura MA, Zöllner C, Mousa SA, Stein, Schäfer M. Characterization of mu opioid receptor binding and $\mathrm{G}$ protein coupling in rat hypothalamus, spinal cord, and primary afferent neurons during inflammatory pain. I Pharmacol Exp Ther 2004; 308:712-718.

21. Jeanjean AP, Moussaoui SM, Maloteaux JM, Laduron PM. Interleukin-1 beta induces long-term increase of axonally transported opiate receptors and substance P. Neurosci 1995; 68:151-157.

22. Ji RR, Zhang Q, Law PY, Low HH, Elde R, Hokfelt T. Expression of mu-delta-, and kappa opioid receptor-like immunore- activities in rat dorsal root ganglia after carrageenan-induced inflammation. J Neurosci 1995; 15:8156-8166.

23. Puehler W, Zöllner C, Brack A, Shaqura MA, Krause $H$, Schäfer $M$, Stein $C$ Rapid upregulation of mu opioid receptor mRNA in dorsal root ganglia in response to peripheral inflammation depends on neuronal conduction. Neuroscience 2004; 129:473-479.

24. Puehler W, Rittner HL, Mousa SA, Brack $A$, Krause H, Stein C, Schäfer M. Interleukin-1 beta contributes to the upreg. ulation of kappa opioid receptor mRNA in dorsal root ganglia in response to peripheral inflammation. Neuroscience 2006; 141:989-998.

25. Mousa SA, Cheppudira BP, Shaqura M, Fischer O, Hofmann J, Hellweg R, Schäfer $M$. Nerve growth factor governs the enhanced ability of opioids to suppress inflammatory pain. Brain 2007; 130:502-513.

26. Barbacid M. Structural and function al properties of the TRK family of neurotrophin receptors. Ann NY Acad Sci 1995; 766:442-458.

27. Inoue N, Hatanaka H. Nerve growth factor induces specific enkephalin binding sites in a nerve cell line. J Biol Chem 1982; 257:9238-9241.

28. Chen YL, Law PY, Loh HH. Sustained activation of phosphatidylinositol 3 -kinase/Akt/nuclear factor \{kappa\}B signaling mediates $\mathrm{G}$ protein-coupled \{delta\}-opioid receptor gene expression. J Biol Chem 2006; 281:3067-3074.

29. Chen YL, Law PY, Loh HH. Action of NFkappaB on the delta opioid receptor gene promoter. Biochem Biophys Res Commun 2007; 352:818-822.

30. Yang J, Lin Y, Guo Z, Cheng J, Huang J, Deng L, Liao W, Chen Z, Liu Z, Su B. The essential role of $\mathrm{MEKK}_{3}$ in TNF-induced NF-kappaB activation. Nat Immunol 2001; 2:620-624.

31. Antonijevic I, Mousa SA, Schäfer M, Stein C. Perineurial defect and peripheral opioid analgesia in inflammation. $J$ Neurosco 1995; 15:165-172.

32. Clark JD, Shi X, Li X, Qiao Y, Liang D, Angst MS, Yeomans DC. Morphine reduced local cytokine expression and neutrophil infiltration after incision. $\mathrm{Mol}$ Pain 2007; 3:28.

33. Brack A, Rittner HL, Machelska $H$, Shaqura M, Mousa SA, Labuz D, Zöllner C, Schäfer M, Stein C. Endogenous peripheral antinociception in early inflammation is not limited by the number of opioid-containing leukocytes but by opioid receptor expression. Pain 2004; 108:67-75.

34. Machelska H, Mousa SA, Brack A, Schopohl JK, Rittner HL, Schafer M, Stein C. Opioid control of inflammatory pain regulated by intercellular adhesion molecule-1. J Neurosci 2002; 22:55885596.

35. von Andrian UH, Mackay CR. T-cell function and migration. Two sides of the same coin. N Eng J Med 2000; 343:1020-1034.

36. Machelska H, Brack A, Mousa SA, Schopohl JK, Rottner HL, Schäfer M, Stein C. Selectins and integrins but not platelet-endothelial cell adhesion molecule1 regulate opioid inhibition of inflammatory pain. Br J Pharmacol 2004;142: 772-780.

37. Mousa SA, Machelska H, Schäfer M, Stein C. Co-expression of $\beta$-endorphin with adhesion molecules in a model of inflammatory pain. J Neuroimmunol 2000; 108:160-170.

38. Brack A, Rittner HL, Machelska K, Leder K, Mousa SA, Schäfer M, Stein C. Control of inflammatory pain by chemokine-mediated recruitment of opioidcontaining polymorphonuclear cells. Pain 2004; 112:229-238.

39. Machelska H, Cabot PJ, Mousa SA, Zhang Q, Stein C. Pain control in inflammation governed by selectins. Nat Med 1998; 4:1425-1426.

40. Brack A, Rittner HL, Machelska H, Beschmann K, Sitte N, Schäfer M, Stein C. Mobilization of opioid-containing polymorphonuclear cells by hematopoietic growth factors and influence on inflammatory pain. Anesthesiology 2004; 100:149-157.

41. Machelska H. Targeting of opioid-producing leukocytes for pain control $\mathrm{Neu}$ ropeptides 2007; 41:355-363.

42. Rittner HL, Lux C, Labuz D, Mousa SA, Schäfer M, Stein C, Brack A. Neurokinin-1 receptor antagonists inhibit the recruitment of opioid-containing leukocytes and impair peripheral antinociception. Anesthesiology 2007; 107:1009-1017.

43. Mousa SA, Shakibaei M, Sitte N, Schäfer M, Stein C. Subcellular pathways of $\beta$-endorphin synthesis, processing, and release from immunocytes in inflammatory pain. Endocrinology 2004; 145:1331-1341.

44. Schäfer M, Carter L, Stein C. Interleukin 1 beta and corticotropin-releasing 
factor inhibit pain by releasing opioids from immune cells in inflamed tissue. Proc Natl Acad Sci USA 1994; 91:42194223.

45. Cabot PJ, Carter L, Gaiddon C, Zhang Q, Schäfer M, Loeffler JP, Stein C. Immune cell-derived $\beta$-endorphin: production, release and control of inflammatory pain in rats. J Clin Invest 1997; 100:142148.

46. Cabot PJ, Carter L, Schäfer M, Stein C. Methionine-enkephalin- and Dynorphin A-release from immune cells and control of inflammatory pain. Pain 2001; 93:207-212.

47. Binder W, Mousa SA, Sitte N, Kaiser M, Stein C, Schäfer M. Sympathetic activation triggers endogenous opioid release and analgesia within peripheral inflamed tissue. Eur J Neurosci 2004; 20:92-100.

48. Rittner HL, Labuz D, Schaefer M, Mousa SA, Schulz S, Schäfer $M$, Stein C, Brack $A$. Pain control by $C X C R 2$ ligands through $\mathrm{CA} 2+$-regulated release of opioid peptides from polymorphonuclear cells. FASEB 2006; 20:2627-2629.

49. Machelska H, Schopoha JK, Mousa SA, Labuz D, Schäfer M, Stein C. Different mechanisms of intrinsic pain inhibition in early and late inflammation. J Neuroimmunol 2003; 141:30-39.

50. Mousa SA, Bopaiah CP, Stein C, Schäfer $M$. Involvement of corticotrophin-releasing hormone receptor subtypes 1 and 2 in peripheral opioid-mediated inhibition of inflammatory pain. Pain 2003; 106:297-307.

51. Mousa SA, Bopaiah CP, Richter JF, Yamdeu RS, Schäfer M. Inhibition of inflammatory pain by CRF at peripheral, spinal and supraspinal sites: Involvement of areas coexpressing CRF receptors and opioid peptides. Neuropsychopharmacology 2007; 32:2530-2542.

52. Rittner HL, Labuz D, Richter JF, Brack A, Schäfer M, Stein C, Mousa SA. CXCR1/2 ligands induce p38 MAPK-dependent translocation and release of opioid peptides from primary granules in vitro and vivo. Brain Behav Immun 2007; 21:1021-1032.

53. Jung $H$, Toth PT, White FA, Miller RJ. Monocyte chemoattractant protein-1 functions as a neuromodulator in dorsal root ganglia neurons. I Neurochem 2008; 104:254-263.

54. White FA, Sun J, Waters SM, Ma C, Ren D, Ripsch M, Steflik J, Cortright DN, La-
Motte RH, Miller RJ. Excitatory monocyte chemoattractant protein-1 signaling is up-regulated in sensory neurons after chronic compression of the dorsal root ganglion. Proc Natl Acad Sci USA 2005; 102:14092-14097.

55. Sun J H, Yang B, Donnelly DF, Ma C, Lamotte RH. MCP-1 enhances excitability of nociceptive neurons in chronically compressed dorsal root ganglia. J Neurophysiol 2006; 96:2189-2199.

56. Abbadie C, Lindia JA, Cumiskey AM, Peterson LB, Mudgett JS, Bayne EK, DeMartino JA, MacIntyre DE, Forrest MJ. Impaired neuropathic pain responses in mice lacking the chemokine receptor CCR2. Proc Natl Acad Sci USA 2003; 100:7947-7952.

57. Garcia-Ramallo E, Marques T, Prats N, Beleta J, Kunkel SL, Godessart N. Resident cell chemokine expression serves as the major mechanism for leukocyte recruitment during local inflammation. J Immunol 2002; 169:6467-6473.

58. Jessop DS. Endomorphins as agents for the treatment of chronic inflammatory disease. BioDrugs 2006; 20:161-166.

59. Zadina JE, Hackier L, Ge LJ, Kastin AJ. A potent and selective endogenous agonist for the mu-opiate receptor. Nature 1997; 386:499-502.

6o. Mousa SA, Machelska H, Schäfer M, Stein C. Immunohistochemical localization of endomorphin-1 and endomorphin-2 in immune cells and spinal cord in a model of inflammatory pain. J Neuroimmunol 2002; 126:5-15.

61. Labuz D, Berger S, Mousa SA, Zöllner C, Rittner HL, Shaqura MA, SegoviaSilvestr T, Przewlocka B, Stein C, Machelska H. Peripheral Aantinociceptive effects of exogenous and immune cellderived endomorphins in prolonged inflammatory pain. J Neurosci 2006; 26:4350-4358.

62. Li ZH, Shan LD, Jiang XH. Analgesic effect of endomorphin-1. Acta Pharmacol Sin 2001; 22:976-980.

63. Cardillo G, Gentilucci L, Qasem AR, Sgarzi F, Spampinato S. Endomorphin1 Analogues Containing $\beta$-Proline are $\mu$ Opioid Receptor are mu-Opioid Receptor Agonsists and Display Enhanced Enzymatic Hydrolysis Resistance. J Med Chem 2002; 45:2571-2578.

64. Spampinato S, Qasem AR, Calienni M, Murari G, Gentilucci L, Tikinekku A, Cardillo $G$. Antinociception by a peripherally administered novel endomorphin-1 analogue containing beta-proline. Eur J Pharmacol 2003; 469:89-95.

65. Labuz D, Mousa SA, Schäfer M, Stein C, Machelska H. Relative contribution of peripheral versus central opioid receptors to antinociception. Brain Research 2007; 1160:30-38.

66. Bergström J, Ahmed M, Li J, Ahmad T, Kreicbergs A, Spetea M. Opioid peptides and receptors in joint tissues: Study in the rat. J Ortho Res 2006; 24:193-1199.

67. Mousa SA, Straub RH, Schäfer M, Stein C. Beta-endorphin, Met-enkephalin and corresponding opioid receptors within synovium of patients with joint trauma, osteoarthritis and rheumatoid arthritis. Ann Rheum Dis 2007; 66:871879.

68. Kalso E, Tramer MR, Carroll D, McQuay HJ, Moore RA. Pain relief from intraarticular morphine after knee surgery: A qualitative systemic review. Pain 1997; 71:127-134.

69. Ness TJ. Pharmacology of peripheral analgesics. Pain Pract 2001; 1:243254.

70. Hassan AHS, Ableitner A, Stein C, Herz A. Inflammation of the rat paw enhances axonal transport of opioid receptors in the sciatic nerve and increases their density in the inflamed tissue. Neuroscience 1993; 55:185-195.

71. Stein C, Yassouridis A. Peripheral morphine analgesia. Pain 1997; 71:119-121.

72. Likar F, Schafer M, Paulak F, Sittl R, Pipam W, Schalk H, Geissler D, Bernatzky G. Intraarticular morphine analgesia in chronic pain patients with osteoarthritis. Anesth Analg 1997; 84:1313-1317.

73. Obara I, Makuch W, Spetea M, Schütz J, Schmidhammer H, Przewlocki R. Local peripheral antinociceptive effects of 14-O-methyloxymorphone derivatives in inflammatory and neuropathic pain in the rat. European Journal of Pharmacology 2007; 558:60-67.

74. Obara I, Przewlocki R, Przewlocka B. Local peripheral effects of mu-opioid receptor agonists in neuropathic pain in rats. Neurosci Lett 2004; 360:85-89.

75. Pertovaara A, Wei H. Peripheral effects of morphine in neuropathic rats: Role of sympathetic postganglionic nerve fibers. Eur J. Pharmacol 2001; 429:139145.

76. Truong W, Cheng C, Xu QG, Li XG, Zochodne DW. Mu opioid receptors and analgesia at the site of a peripheral 
nerve injury. Ann Neurol 2003; 53:366375.

77. Rashid MH, Inoue M, Toda K, Ueda H. Loss of peripheral morphine analgesia contributes to the reduced effectiveness of systemic morphine in neuropathic pain. J Pharmacol Exp Ther 2004; 309:380-387.

78. Schütz J, Spetea M, Koch M, Aceta MD, Harris LS, Coop A, Schmidhammer H.
Synthesis and biological evaluation of 14-alkoxymorphinans. 20. 14-phenylpropoxymetopon: An extremely powerful analgesic. I Med Chem 2003; 46:4182-4187.

79. Spetea M, Friedmann T, Riba P, Schütz J, Wunder G, Langer T, Schmidhammer $\mathrm{H}$, Fürst $\mathrm{S}$. In vitro opioid activity profiles of 6-amino acid substituted derivatives of $14-0$-methyloxymorphone.
Eur J Pharmacol 2004; 483:301-308.

80. Fürst S, Riba P, Friedmann J, Timar J, AlKhrasani M, Obara I, Makuch W, Spetea M, Schütz J, Przewlocki R, Przewlocka $B$, Schmidhammer H. Peripheral versus central antinociceptive actions of 6amino acid-substituted derivatives of 14-0-methyloxymorphone in acute and inflammatory pain in the rat. I Pharmacol Exp 2005; 312:609-618. 